\title{
Nanocrystals: Solution-Based Synthesis and Applications as Nanocatalysts
}

\author{
Dingsheng Wang, Ting Xie, and Yadong Li ( $\varangle)$ \\ Department of Chemistry, Tsinghua University, Beijing 100084, China \\ Received: 28 October 2008 / Revised: 27 November 2008 / Accepted: 27 November 2008 \\ CTsinghua University Press and Springer-Verlag 2009. This article is published with open access at Springerlink.com
}

\begin{abstract}
Nanocrystals are emerging as key materials due to their novel shape- and size-dependent chemical and physical properties that differ drastically from their bulk counterparts. The main challenges in this field remain rationally controlled synthesis and large scale production. This article reviews recent progress in our laboratory related to solution-based synthesis of various nanostructures, including zero-dimensional (0-D) nanocrystals, 1-D nanowires and nanorods, hollow structures, and superlattice materials. On the other hand, the essential goal for nanoresearchers is to achieve industrial applications of nanostructured materials. In the past decades, these fascinating materials have been widely used in many promising fields such as nanofabrication, nanodevices, nanobiology, and nanocatalysis. Herein, we focus on their applications as nanocatalysts and try to illustrate the main problems and future directions in this area based on our recent endeavors in catalytic applications of nanocrystals.
\end{abstract}

\section{KEYWORDS}

Nanocrystals, solution-based synthesis, nucleation and growth mechanism, nanocatalysts

\section{Introduction}

It is well known that, at the nanoscale, materials exhibit fascinating optical, electronic, and magnetic properties that differ drastically from their bulk counterparts [1-6]. A typical example is gold, which in the bulk form is a non-magnetic, yellow noble metal. In contrast, $10 \mathrm{~nm}$ Au particles absorb green light and thus appear red, 2-3 nm Au particles exhibit considerable magnetism, and smaller Au particles can even turn into insulators [7]. The novel properties of nanostructured materials enable them to find potential applications in many new and promising fields such as nanofabrication, nanodevices, nanobiology, and nanocatalysis [8-13]. For example, multifunctional nanoparticle probes based on semiconductor quantum dots (CdSe-ZnS core-shell QDs) have been developed for cancer targeting and imaging in living animals by the Nie group [14], Lieber et al. reported the realization of p-type/ intrinsic/n-type $(\mathrm{p}-\mathrm{i}-\mathrm{n})$ coaxial silicon nanowire solar cells which yielded a maximum power output of up to $200 \mathrm{pW}$ per nanowire device and an apparent energy conversion efficiency of up to $3.4 \%$ under one solar equivalent (1-sun) illumination [15] and platinum nanocrystals with unusual tetrahexahedral

Address correspondence to ydli@mail.tsinghua.edu.cn 
shape were prepared by Wang and co-workers which exhibited thermal (to $800{ }^{\circ} \mathrm{C}$ ) and chemical stability and much enhanced (up to $400 \%$ ) catalytic activity for equivalent $\mathrm{Pt}$ surface areas for electro-oxidation of small organic fuels such as formic acid and ethanol [16]. Therefore, over the past decades, synthesis of nanometer-size crystallites has been among the key research topics pursued worldwide by scientists in the fields of nanoscience and nanotechnology.

Two different kinds of methods have been developed for the preparation of nanocrystals: dry routes which include physical strategies such as various lithography techniques and chemical strategies such as the atmospheric pressure chemical vapor deposition (APCVD) approach, and wet routes including various solution-based chemical strategies such as the hot-injection method, the microemulsion method, and the sol-gel method. The lithography techniques belong to the "top-down" approach, which removes material from the bulk, leaving only the desired nanostructures. They are fairly expensive and time consuming, especially for generation of samples with large surface areas [1718]. The APCVD method belongs to the "bottom-up" approach, which starts from atomic-level precursors and results in new compounds by formation of new chemical bonds. It requires complicated apparatus and yields nanocrystals in small amounts and with low productivity [19-22]. In contrast, the solutionbased chemical process for nanocrystal synthesis is much more flexible [23-25]. In 1993, Bawendi and coworkers presented a simple hot-injection route for the production of high quality cadmium chalcogenide semiconductor nanocrystallites based on the pyrolysis of organometallic reagents by injection into a hot coordinating solvent [26]. The use of neutral organometallic precursors and coordinating solvents with a high boiling point provides temporally discrete nucleation and growth, and the organic capping ligands prevent aggregation of the particles at the nanoscale and improve the chemical stability of the formed nanocrystals. This wet hot-injection strategy represented a clear break with previous synthetic methods in the sense of producing nanocrystals with a high degree of monodispersity, which opened the door to the preparation of a wide range of high quality monodisperse nanocrystals using various solution-based methods [27-31].

Successful syntheses of nearly all kinds of nanostructured materials, including metals, metal oxides, and semiconductors, have now been realized [32-37]. However, there are still two main challenges remaining in this field, rationally controlled synthesis and large scale production. On one hand, the properties of materials at the nanoscale can be profoundly affected by the shape and size of the nanostructures due to surface effects and quantum size effects [38]. An archetypal example is that the photoluminescent properties of semiconductor quantum dots can be tuned through varying the particle size. Alivisatos and co-workers synthesized a series of CdSe quantum dots with diameters of 2.1, 2.4, 3.1, 3.6, and $4.6 \mathrm{~nm}$, whose emission wavelength changed from green to red [39]. So, precise control over the shape and size of nanocrystals is very important. Actually, controlled synthesis of nanostructured materials has been achieved by many solution-based methods [40-45]. For example, Peng et al. demonstrated that control of the growth kinetics of the II-IV semiconductor CdSe via adjusting monomer concentration could be used to vary the shapes of the resulting particles from a nearly spherical morphology to a rodlike one, with aspect ratios as large as ten to one [46]; the O'Brien group synthesized monodisperse $\mathrm{MnO}$ nanocrystals by thermal decomposition of manganese acetate in the presence of oleic acid at $320{ }^{\circ} \mathrm{C}$ and showed that the particle size could be adjusted from 12 to $20 \mathrm{~nm}$ by controlling the aging time [47]; Hyeon and co-workers also reported a one nanometer-level diameter-controlled synthesis of monodisperse magnetic iron oxide nanocrystals obtained by seed-mediated growth of previously synthesized monodisperse nanoparticle seeds [48]. Although these exciting results provide effective strategies for the synthesis of nanocrystals with controllable shape and size, what is still required is much more rational control over the nanocrystals, namely, the ability to design and optimize nanostructures at will. On the other hand, from an industrial perspective, economical mass production of nanocrystals is necessary to meet the 
demand for future applications of nanomaterials. Unfortunately, many synthetic methods developed in the past decades, although effective in producing nanocrystals with high quality and good monodispersity, can provide only sub-gram quantities of samples in the laboratory. So, we and many other groups have recently been inspired to address this challenge by developing much more effective and economical synthetic strategies. In 2004, the Hyeon group reported the ultralarge scale synthesis of monodisperse nanocrystals (as much as $40 \mathrm{~g}$ of sample in a single reaction without a size sorting process) via the thermal decomposition of metal-oleate precursors in high boiling solvents [49]. Recently, a general liquid-solid-solution phase transfer and separation strategy for nanocrystals was developed by our group [50]. In this approach, a water-ethanol mixed solution is adopted as the main continuous solution phase and inorganic salts are used as the starting materials. Because of the high solubility of inorganic salts in water, this solutionbased method is a promising way of providing gram-scale nanocrystals in the laboratory and can be expanded to the industrial scale in a simple way.

In the present contribution, we first provide a brief account of our own recent efforts to synthesize nanocrystals using solution-based methods. By utilizing simple chemical reactions (decomposition reactions, redox reactions, etc.), choosing appropriate reaction systems (solvent, surfactant, etc.), and controlling reaction parameters (monomer concentration, reaction temperature, reaction time, etc.), we have obtained many different kinds of nanostructures (0-D nanocrystals, 1-D nanowires and nanorods, hollow structures, superlattice structures, etc.) of various materials (metals, metal oxides, semiconductors, etc.). The size and morphology of the nanocrystals can be precisely controlled by tuning the reaction conditions and some strategies can even produce hundreds of grams of high quality monodisperse nanocrystals in the laboratory. Subsequently, we focus on the catalytic applications of nanocrystals and summarize our recent endeavors in the study of nanocatalysts. Some examples are given to illustrate the main problems and future directions in this promising field.

\section{Solution-based synthesis of nanocrystals}

Solution-based chemical synthetic strategies provide simple and powerful routes to nanocrystals. They are quite general, allowing the preparation of all kinds of nanomaterials and usually have the advantages of greater capability and flexibility compared to the dry synthetic routes. However, in the absence of hard templates or catalysts, wet chemical procedures are far more difficult to control. According to the suggestions of LaMer and co-workers in the early 1950s [51], in order to prepare highly monodisperse nanocrystals, it is necessary to effectively separate nucleation and growth into two distinct steps and precisely control the two separate processes by tuning the thermodynamic and kinetic parameters of the reactions. In most cases, a simple chemical reaction and the corresponding precursors are first selected based on the target nanocrystals. We then design a rational reaction system including the kind of solvent-adopted and surfactant-employed and utilize an appropriate nucleation technique such as a hot-injection or heating up method to achieve a "burst nucleation" process which induces rapid and instantaneous nucleation and prevents additional nucleation occurring during the subsequent growth process. Subsequently, many critical experimental parameters that have great influence on the growth behavior of the nanocrystals including reactant concentration, reaction temperature, reaction time, $\mathrm{pH}$, and the molar ratio of precursor to capping ligand are precisely adjusted to achieve rational control over the size and morphology of the nanocrystals in the crystal growth step. Here, we apply appropriate solution-based strategies for various nanostructures including 0-D nanocrystals, 1-D nanowires and nanorods, hollow structures, and superlattice materials in order to demonstrate the potentialities of this kind of nanosynthesis technique. Furthermore, in order to understand the nucleation and growth of nanocrystals in the solution, we discuss the mechanism responsible for shape and size control of the nanocrystals obtained from our solution-based syntheses. 


\subsection{Nanostructures obtained using appropriate solution-based strategies}

The first example is the multigram scale synthesis of ultrafine monodisperse $\mathrm{CeO}_{2}$ nanocrystals [52]. The decomposition of $\left(\mathrm{NH}_{4}\right)_{2} \mathrm{Ce}\left(\mathrm{NO}_{3}\right)_{6}$ was employed as the chemical reaction, while a waterethanol mixed solvent and oleic acid as surfactant were chosen as the reaction system. In the synthesis process, $\left(\mathrm{NH}_{4}\right)_{2} \mathrm{Ce}\left(\mathrm{NO}_{3}\right)_{6}$ released $\mathrm{Ce}\left(\mathrm{NO}_{3}\right)_{6}{ }^{2-}$ anions in the water-ethanol mixed solvent. The anion possesses a stable icosahedral structure, as shown in Fig. 1(a), with the twelve apical oxygen atoms of the icosahedron being provided by six bidentate nitrate liands and $\mathrm{Ce}^{4+}$ located at the centre of the icosahedron. Such a natural cage constructed by the oxygen atoms effectively slows down the rate of hydration of $\mathrm{Ce}^{4+}$, and continuously maintains an appropriate reaction rate. During decomposition of the icosahedral structure, oleate ions, generated in situ by reaction between $\mathrm{NaOH}$ and oleic acid, become adsorbed on the surface of $\mathrm{CeO}_{2}$ nanocrystals through ion exchange. The competition between coordination of oleate ion and nitrate ions offers sufficient time for an Ostwald ripening process of the nanocrystals, leading to the formation of highly monodisperse $\mathrm{CeO}_{2}$ nanoparticles capped by oleic acid surfactant moieties which endow the individual nanoparticles with a hydrophobic surface. These nonpolar uniform particles precipitate from the bulk polar solution and the residual $\mathrm{Ce}\left(\mathrm{NO}_{3}\right)_{6}{ }^{2-}$ anions in solution continuously produce more particles. Due to the high solubility of $\left(\mathrm{NH}_{4}\right)_{2} \mathrm{Ce}\left(\mathrm{NO}_{3}\right)_{6}$ in aqueous solution, we can prepare even $300-400 \mathrm{~g}$ of high quality samples in a one-pot synthesis. Figures 1(b) and 1(c) show transmission electron microscopy (TEM) images of the as-obtained $\mathrm{CeO}_{2}$ nanocrystals at different magnification, from which we can see that these oxide nanocrystals are monodisperse, nearly spherical particles with an average diameter of only $2.9 \mathrm{~nm}$. Other 0 -D metal, metal oxide, and metal chalcogenide nanocrystals can also be prepared by suitable solution-based routes [53-55].

1-D nanomaterials, including nanowires and nanorods, are highly attractive building blocks for nanodevices due to their inherent anisotropies and efficient transport of electrons and excitons within their smallest dimension [56-59]. We applied $\mathrm{AgNO}_{3}$ and elemental $\mathrm{S}$ as reactants and designed a reaction system composed of a single component, octadecylamine (ODA), which served as both the solvent and the surfactant. The shape of the $\mathrm{Ag}_{2} \mathrm{~S}$ product can be controlled from 0-D particles to 1-D wires by changing the precursor concentration [56]. As demonstrated by scanning electron microscopy (SEM), TEM, and high resolution TEM (HRTEM) images of the samples (Figs. 2(a) and 2(d)), wellcrystallized $\mathrm{Ag}_{2} \mathrm{~S}$ nanowires were produced in high yield with diameters in the range 10-30 nm and lengths up to hundreds of micrometers. Figure 2(e) illustrates the relationship between precursor concentration and crystal morphology. When the concentration is low, the sulfur atoms have comparatively low probability of colliding with $\mathrm{Ag}^{+}$. Therefore, $\mathrm{Ag}_{2} \mathrm{~S}$ nuclei formed in situ will be completely capped by ODA before the next collision. The ligands on the surface can prevent $\mathrm{Ag}_{2} \mathrm{~S}$ nuclei from aggregating which leads to the formation of 0-D nanoparticles. As the concentration increases, the system will have higher chemical potential and

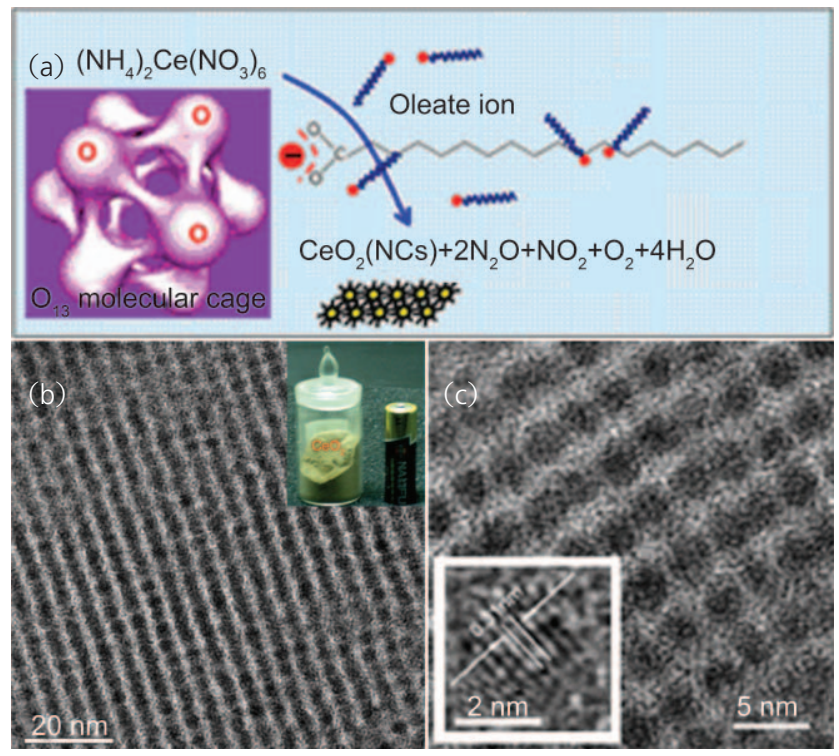

Figure 1 (a) View of the icosahedral structure of $\mathrm{Ce}\left(\mathrm{NO}_{3}\right)_{6}{ }^{2-}$ and the synthesis scheme for $\mathrm{CeO}_{2}$ nanocrystals (NCs); (b) TEM image of the product at low magnification; the inset shows a digital camera image of the product in relation to an AA battery; (c) TEM image of the product at high magnification; the inset shows an HRTEM image of an individual nanocrystal. Adapted from Ref. [52] 
the collision probability between $\mathrm{S}$ and $\mathrm{Ag}^{+}$increases greatly. Thus, before $\mathrm{Ag}_{2} \mathrm{~S}$ nuclei can be completely protected by the surfactants, they can adsorb more sulfur atoms in one specific orientation, which leads to the formation of 1-D nanowires. Other parameters such as the reaction temperature can also influence the crystal evolution process in solution system. Particular combinations of conditions are needed to prepare pure particles or wires.

Cage-structured nanomaterials with hollow interiors and functional surfaces have attracted broad attention from researchers in recent years due to their great potential for the encapsulation of guest molecules and the resulting applications in various fields such as biotechnology, drug delivery, and nanometer-scale reactors $[60,61]$. We have

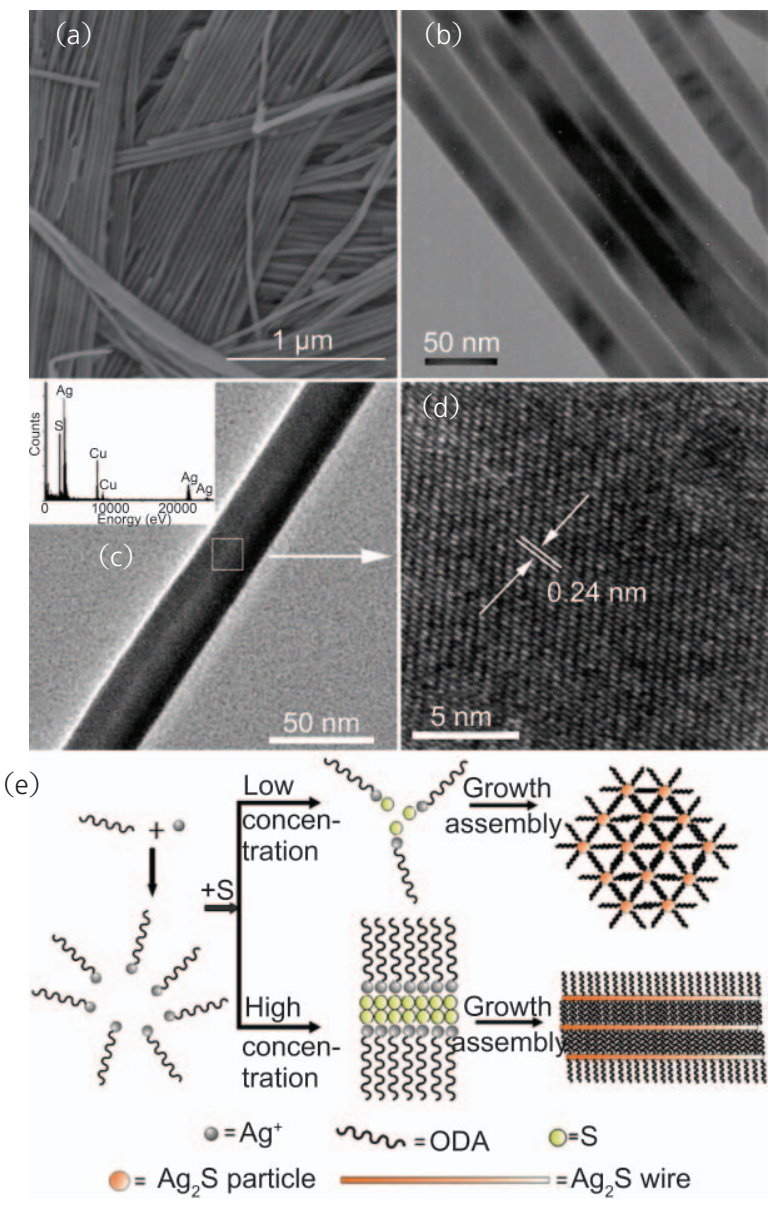

Figure 2 (a) SEM and and (b) TEM images of well-aligned ultralong $\mathrm{Ag}_{2} \mathrm{~S}$ nanowires; (c) HRTEM image of an individual $\mathrm{Ag}_{2} \mathrm{~S}$ nanowire, inset: EDS analysis of the wire; (d) crystal lattice image of an individual $\mathrm{Ag}_{2} \mathrm{~S}$ nanowire; (e) schematic illustration showing the effect of experimental parameters on the shape and size of $\mathrm{Ag}_{2} \mathrm{~S}$ crystals. Adapted from Ref. [56] successfully prepared a novel hollow $\mathrm{CeO}_{2}-\mathrm{ZrO}_{2}$ nanocomposite with controllable structure by a simple solution phase process [60]. Monodisperse ceria nanospheres with different shapes fabricated through a hydrolysis route in glycol were used as precursors, and zirconium (IV) was added to react with the monodisperse ceria nanospheres in the glycol medium to form $\mathrm{CeO}_{2}-\mathrm{ZrO}_{2}$ nanocages utilizing the Kirkendall effect. Figure 3(a) illustrates the complete morphology evolution process according to the Kirkendall effect. The Kirkendall effect states that each species has its own diffusion rate in a diffusing system. When $\mathrm{Zr}^{4+}$ ions were added into the system, they readily doped into ceria to form a solid solution of the type $\mathrm{Ce}_{1-x} \mathrm{Zr}_{x} \mathrm{O}_{2}$; meanwhile, the diffusion rate of the special secondary nanostructure of the
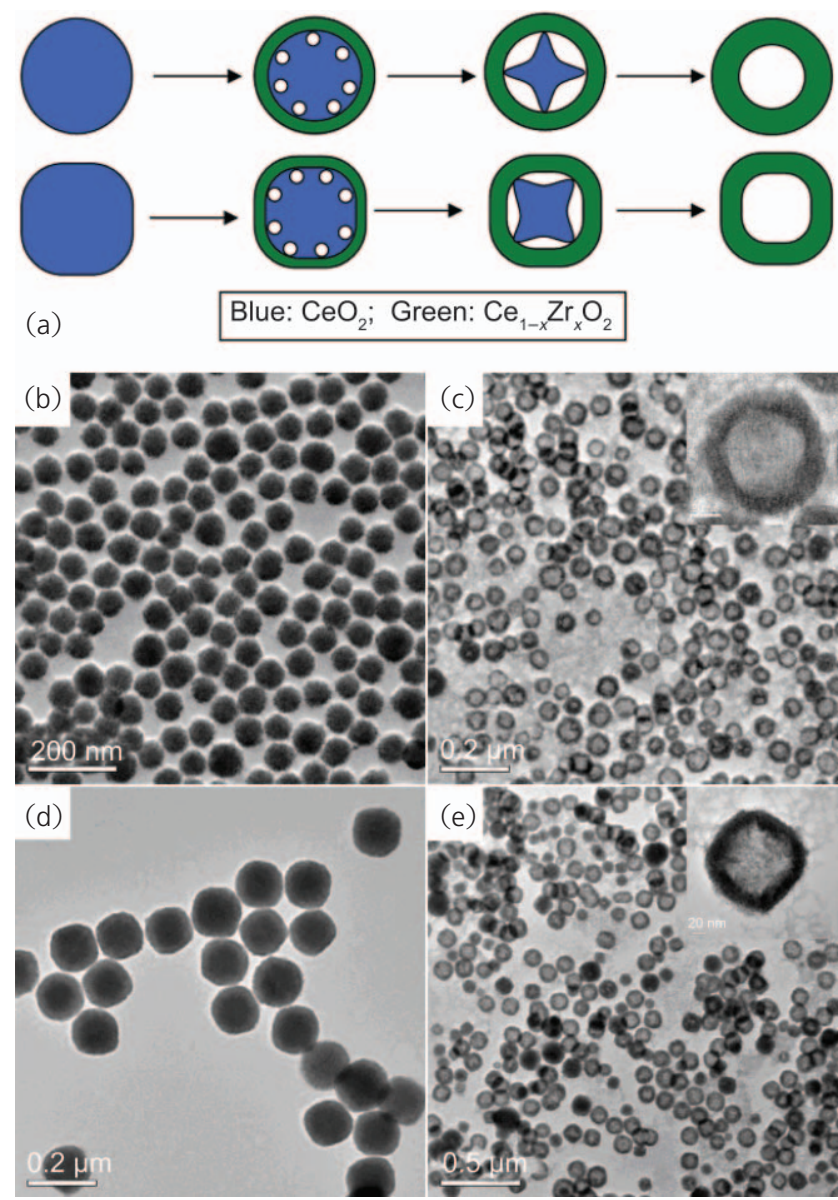

Figure 3 (a) Schematic illustration of the formation process for $\mathrm{Ce}-\mathrm{Zr}-\mathrm{O}$ nanocages based on the Kirkendall effect. TEM images of (b) nearly monodisperse spherical ceria nanocrystals and (c) the corresponding $\mathrm{Ce}-\mathrm{Zr}-\mathrm{O}$ nanocages. TEM images of (d) nearly cubiclike ceria nanocrystals and (e) the corresponding $\mathrm{Ce}-\mathrm{Zr}-\mathrm{O}$ nanocages. Adapted from Ref. [60] 
resulting clusters was obviously much faster than that of the single-element nanostructure, leading to the formation of hollow nanostructures of the $\mathrm{Ce}_{1-x} \mathrm{Zr}_{x} \mathrm{O}_{2}$ type. Figures 3(b)-(e) show representative TEM images of nearly monodisperse spherical and cubic-like ceria nanocrystal clusters obtained at different water concentrations and the corresponding $\mathrm{Ce}-\mathrm{Zr}-\mathrm{O}$ nanocages, from which we can see that the morphologies of the nanocages and the hollow interiors have been determined by the morphology of the ceria templates. When spherical ceria clusters (Fig. 3(b)) were used as precursors, spherical nanocages (Fig. 3(c)) were obtained, while cubic nanocages (Fig. $3(\mathrm{e})$ ) were formed when nearly cubic ceria clusters (Fig. 3(d)) were used as precursors.

Superlattice structures assembled from monodisperse nanocrystals are gaining more and more attention due to their tunable collective physical and chemical properties and they are the basis for future nanomaterials and nanodevices. Generally, the processes for assembly of superlattice structures include two steps: precise control over the composition, size, shape, and surface chemistry of the nanocrystal building blocks and subsequent slow vaporization of the solvent to induce assembly of nanoparticles on the substrate or template; these are complex and limit the development of research into superlattice assemblies. Solution-based strategies can achieve a facile one-step construction of superlattices such as tetrahedral 3-D superlattice colloidal crystals of $\mathrm{Ag}_{2} \mathrm{~S}[62,63]$. We adopted dodecanethiol as both $\mathrm{S}$ source and structure-directing agent and designed a two-phase reaction system: the aqueous phase containing the Ag source $\left(\mathrm{Ag}\left(\mathrm{NH}_{3}\right)_{2}^{+}\right)$and the oil phase (dodecanethiol) which itself provided the $\mathrm{S}$ source. A silver dodecanethiol complex formed at the water/oil interface and decomposed to $\mathrm{Ag}_{2} \mathrm{~S}$ nanocrystals as the temperature was increased to $200{ }^{\circ} \mathrm{C}$. These in situ generated nanocrystals capped by dodecanethiol self-assembled at the interface of water and dodecanethiol and formed hexagonal close packed layers. Then, several layers packed together to give 2-D cubic close packed superlattice (SL) flakes which break along the lowest energy face $\{111\}_{\mathrm{SL}}$ to form triangle-shaped superlattices when they grow sufficiently large. The free nanocrystals in the solution stack over the triangle substrate layer by layer to form a 3-D superlattice, and finally generate a tetrahedral colloidal crystal to minimize the surface energy (Fig. 4(a)). Figures 4(b) and 4(d) show TEM and HRTEM images of the products. It is obvious from these images that the tetrahedra with average edge length of $400 \mathrm{~nm}$ are built up from uniform nanocrystals which have an average diameter of about $3.5 \mathrm{~nm}$ and are ordered in a close-packed manner to construct a 3-D superlattice structure.
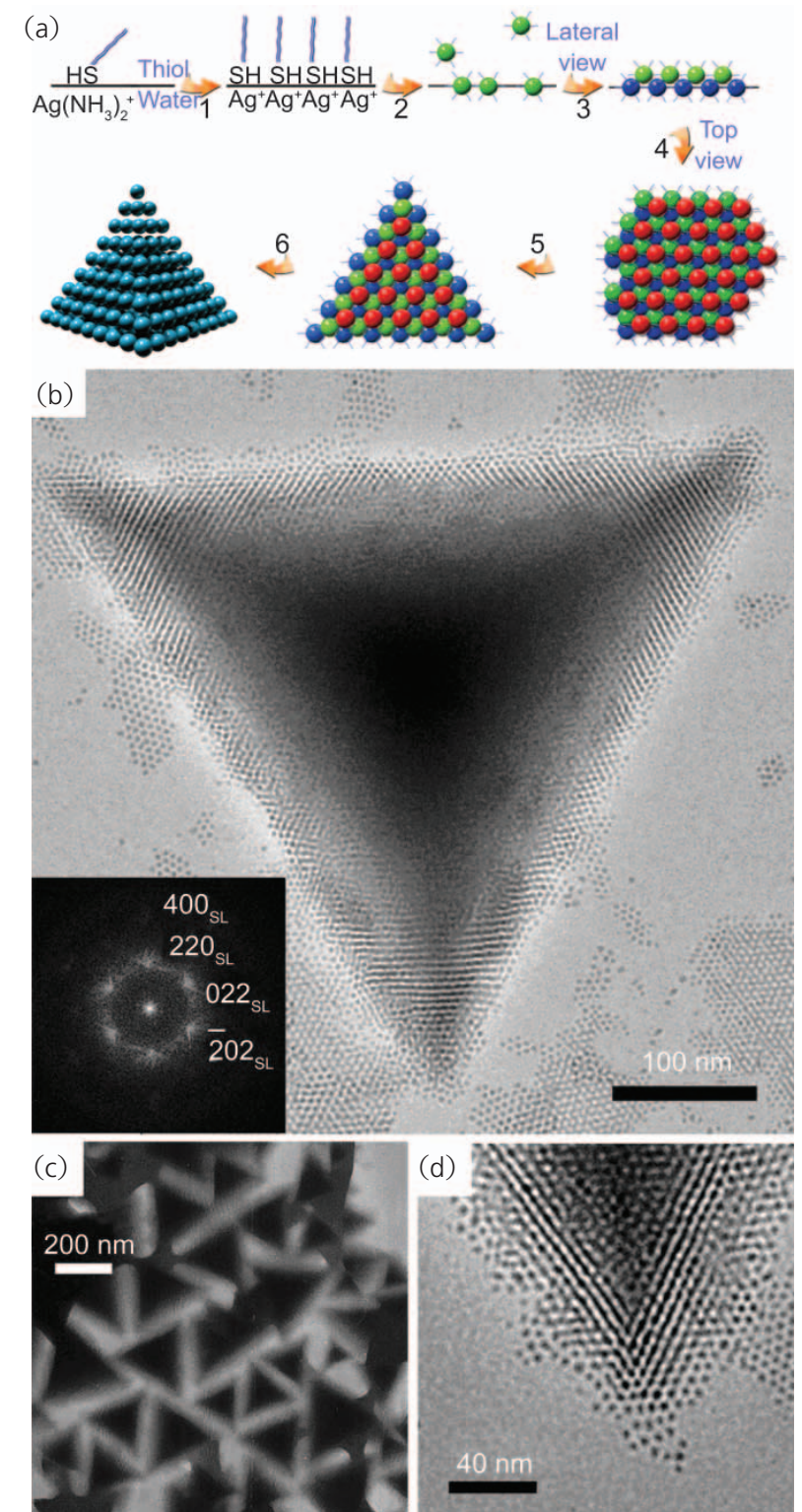

Figure 4 (a) Schematic illustration of the possible formation mechanism for tetrahedral superlattice colloidal crystals; (b) a typical HRTEM image of an individual tetrahedron; the inset is the FFT pattern of the superlattice; (c) TEM image of the resulting $\mathrm{Ag}_{2} \mathrm{~S}$ tetrahedral superlattice colloidal crystals; (d) a magnified HRTEM image of a corner of the tetrahedron. Adapted from Ref. [62] 


\subsection{Nucleation and growth mechanism for nano- crystals}

Understanding the underlying growth mechanism for nanocrystals assists us in gaining the ability to rationally synthesize nanomaterials with greater control, which in turn serves as a key enabler of next-generation materials technologies. Although the process of nanocrystal nucleation and growth in solution systems is indeed complicated, controlled synergistically by thermodynamics and kinetics, we can identify these two factors and use fundamental formulae and equations in physical chemistry to understand the relationship between the experimental parameters and the final size and shape of products. On this basis, our group has recently developed two models: the surface chemical thermodynamics (SCT) model and the diffusion-controlled kinetic (DCK) model based on thermodynamics and kinetics, respectively, to interpret qualitatively the effects of varying the reaction conditions on the size transition and morphology evolution of fluoride nanocrystals.

The effect of initial precursor concentrations on the nucleation and growth of $\mathrm{BaF}_{x} \mathrm{Cl}_{2^{-} x}$ nanocrystals were investigated [43]. It was found that the specific surface area of the resultant nanowires/ nanorods increased as the initial concentrations increased (shown in Fig. 5). Figure 6 shows the variation in calculated surface atom ratio with precursor concentration. The observed experimental phenomena can be explained qualitatively using the SCT model, based on the fundamental thermodynamic equation:

$$
\mathrm{d} G=-S \mathrm{~d} T+V \mathrm{~d} p+\gamma \mathrm{d} \sigma+\sum_{i=1}^{n} \mu_{\mathrm{Bi}} \mathrm{d} n_{\mathrm{Bi}}
$$

in which $\mu$ is the chemical potential, $\sigma$ is the surface area, and $\gamma$ represents the specific surface energy, which is negative under such conditions. Through reasonable derivation and approximation, we came to the conclusion:

$$
-\gamma \Delta \sigma=\int_{i}^{f} \sum_{i=1}^{n} \mu_{\mathrm{Bi}} \mathrm{d} n_{\mathrm{Bi}}<0
$$

which indicates that increasing the initial concentrations will lead to an increase in the specific surface area of the nanocrystals.

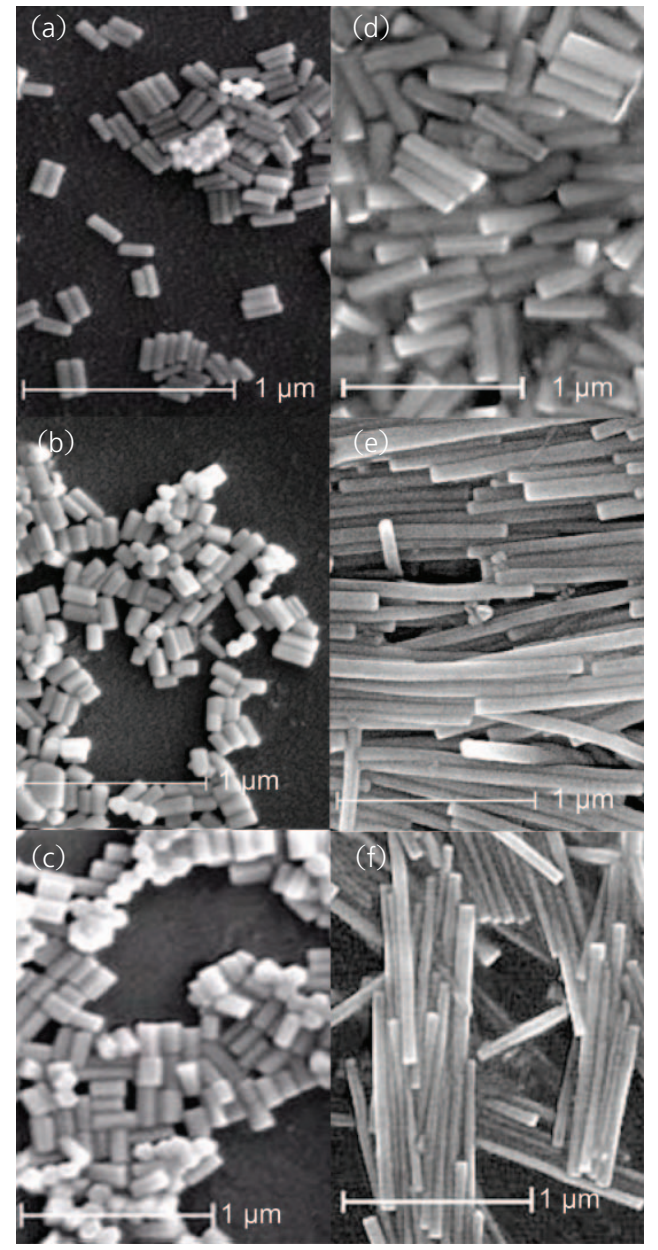

Figure 5 Representative TEM images of $\mathrm{Ba}_{2} \mathrm{~F}_{3} \mathrm{Cl}$ nanorods obtained with varying concentrations of $\mathrm{Ba}^{2+}$ and all other reactant concentrations remaining at a constant ratio to $\mathrm{Ba}^{2+}$. The initial concentrations of $\mathrm{Ba}^{2+}$ are (a) $0.100 \mathrm{~mol} / \mathrm{L}$, (b) $0.0875 \mathrm{~mol} / \mathrm{L}$, (c) $0.075 \mathrm{~mol} / \mathrm{L}$, (d) $0.050 \mathrm{~mol} / \mathrm{L}$, (e) $0.0375 \mathrm{~mol} / \mathrm{L}$, and (f) $0.025 \mathrm{~mol} / \mathrm{L}$. Adapted from Ref. [43]

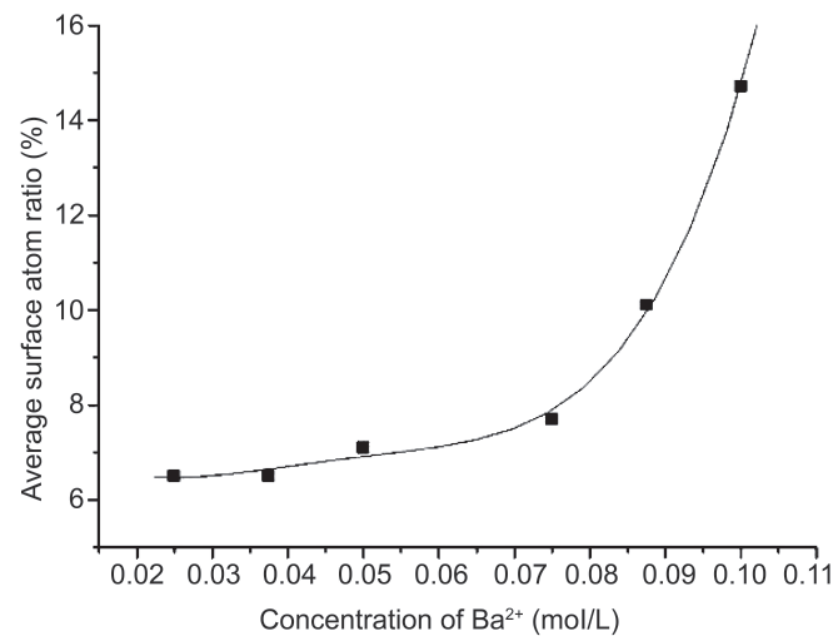

Figure 6 Concentration dependence of the surface atom ratio of $\mathrm{Ba}_{2} \mathrm{~F}_{3} \mathrm{Cl}$ nanocrystals. Higher initial concentrations lead to increased surface atom ratios. Adapted from Ref. [43] 
The DCK model measures the kinetics-dominated size transition and morphology evolution of nanocrystals under non-equilibrium conditions [45]. It starts from the growth rate equations:

$$
\left\{\begin{array}{l}
g_{1}=D_{1} V_{\mathrm{m}} R_{\text {eff }}^{-1}[A]^{a_{1}} \\
g_{2}=D_{2} V_{\mathrm{m}} R_{\text {eff }}^{-1}[A]^{a_{2}}
\end{array}\right.
$$

where the subscripts 1 and 2 represent the longitudinal and radius directions, respectively; $D_{i}$ are diffusion coefficients; $V_{\mathrm{m}}$ is the molar volume of the solid nanocrystal; $[A]$ is the nanocrystal monomer concentration; $a_{i}$ are reaction orders. If $g_{1}<g_{2}$, the $\mathrm{BaF}_{2}$ nucleus undergoes $3-\mathrm{D}$ growth, and forms complete cubic $\mathrm{BaF}_{2}$ nanoparticles via Ostwald ripening (see Fig. 7). When $g_{1}>g_{2}, 1$-D growth predominates, which leads to $L_{1}>L_{2}$, and growth of orthorhombic phase $\mathrm{BaF}_{2}$ nanorods in an epitaxial manner (shown in Fig. 8). The overall process is summarized in Fig. 9.

By interpreting qualitatively the effects of varying the reaction conditions on the size and shape of nanocrystals, we can reveal-to some extent-their underlying nucleation and growth mechanism based on either thermodynamics or kinetics. Our efforts towards understanding the fundamentals of nanocrystal nucleation and growth should lead to greater control over crystal morphology and composition.

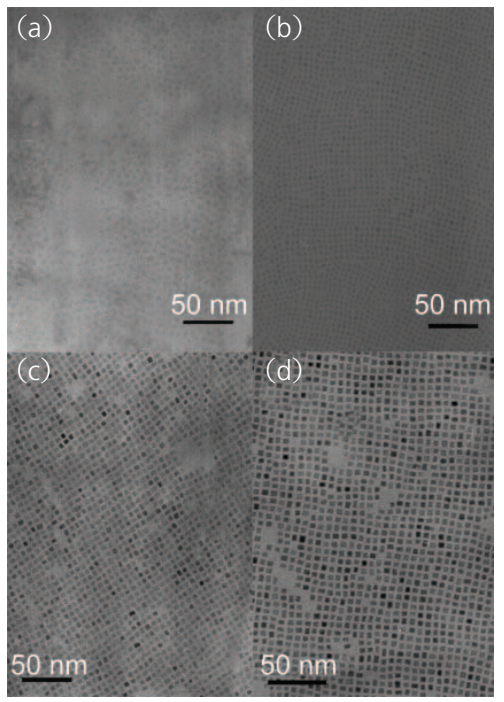

Figure 7 TEM images showing the nucleation and growth of cubic phase $\mathrm{BaF}_{2}$. The ripening time is (a) $10 \mathrm{~min}$, (b) 12 h, (c) 24 h, and (d) 48 h. Adapted from Ref. [45]

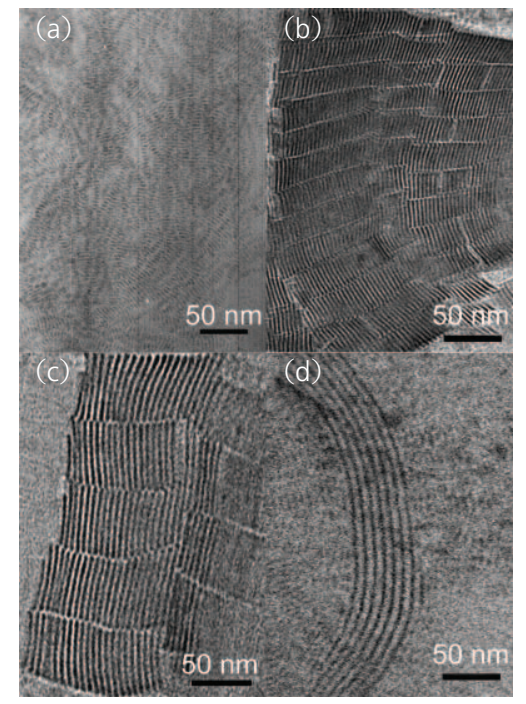

Figure 8 TEM images illustrating the nucleation and growth of orthorhombic phase $\mathrm{BaF}_{2}$. The ripening time is (a) $10 \mathrm{~min}$, (b) $4 \mathrm{~h}$, (c) $8 \mathrm{~h}$, and (d) $12 \mathrm{~h}$. Adapted from Ref. [45]

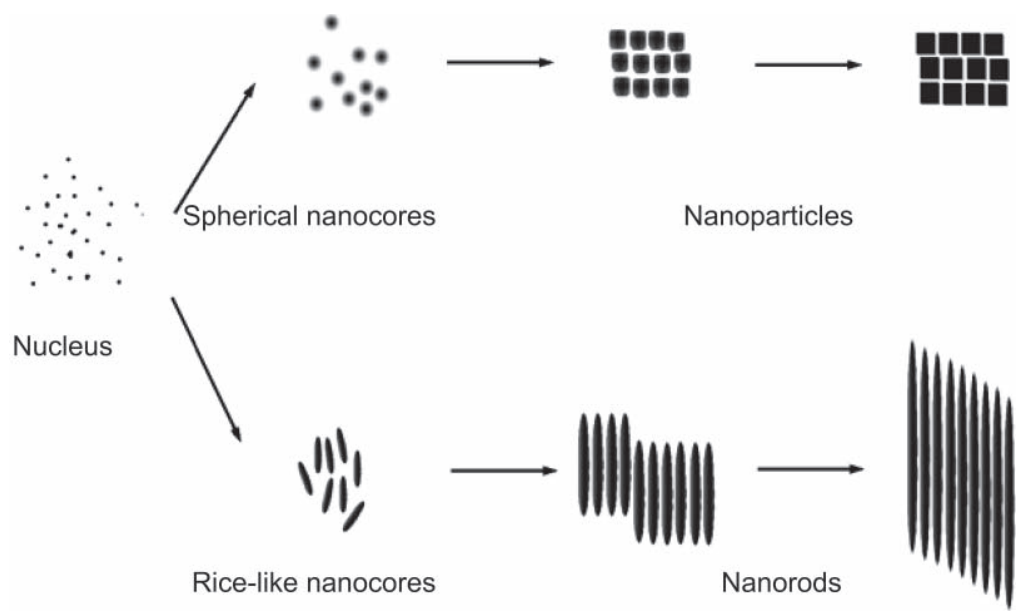

Figure 9 Schematic illustration of the formation and morphology of cubic phase and orthorhombic phase $\mathrm{BaF}_{2}$. Adapted from Ref. [45].

\section{Applications of nanocrystals as nanocatalysts}

Catalysis is a very old but still active research field, which is extremely important for humankind. Undoubtedly, the emergence and development of nanoscience and nanotechnology bring new opportunities to this area. As early as 1989, nanoscale Au particles were shown to be catalytically active for low-temperature $\mathrm{CO}$ oxidation by the Haruta group for the first time [64]. This result changed the conventional idea that $\mathrm{Au}$ is always very unreactive, as it is in the bulk state, and opened the door to interesting applications of nanoscale materials in catalysis. In the following years, nanocatalysts attracted more and more attention worldwide. For example, Goodman and co-workers investigated size effects on the catalytic activity of supported Au clusters for the $\mathrm{CO}$ oxidation reaction in detail and suggested that $\mathrm{Au}$ clusters around 3.5 $\mathrm{nm}$ exhibited the maximum reactivity [65]. Nowadays, advanced synthetic techniques for nanocrystals have greatly accelerated the development of nanocatalysts [66-69]. However, there are still many problems puzzling scientists in this field. One is to understand the most 
important parameters influencing the performance of nanocatalysts so as to prepare catalysts with high activity and selectivity. For a long time, the excellent catalytic performance of nanomaterials has been attributed to the large surface area due to their small size. Although this idea was traditionally accepted, some experiments have shown unusual results in recent years [70,71], a typical example being the different activities for $\mathrm{CO}$ oxidation of particle-shaped and rod-shaped $\mathrm{CeO}_{2}$ nanocatalysts [71]. Because the predominantly exposed planes are the unusually reactive $\{001\}$ and $\{110\}$ planes in the $\mathrm{CeO}_{2}$ nanorods rather than the stable $\{111\}$ planes in the irregular nanoparticles, the $\mathrm{CeO}_{2}$ nanorods are more reactive for $\mathrm{CO}$ oxidation than their counterparts although the surface area of the latter is higher than that of the former. This result demonstrates that exposure of specific crystal planes of nanocrystals is indeed an essential factor in determining their catalytic performance, indicating that the ideal nanosynthesis will increase the number of more reactive crystal planes and decrease the number of less reactive ones rather than just increase the total surface area. However, this has turned out to be a very difficult task for most practical catalysts. Another key problem concerns the stability of nanocatalysts, especially for supported noble metal catalysts which are the most important catalysts in industrial applications. From an industrial perspective, catalysts should be recycled as many times as possible and it is crucial to retain the high activity of catalysts in each cycle. As mentioned above, the catalytic activity of noble metals such as $\mathrm{Au}$ is greatly related to the particle size $[65,72,73]$. Unfortunately, it is very hard to keep the particle size unchanged during the reaction process. The metal particles will usually aggregate and the particle size will become larger, leading to catalyst deactivation, even when they are prepared by the most successful deposition-precipitation methods available so far. On the other hand, the interactions between the noble metals and the supports also play a critical role in the stability of catalyst performance. Usually, the metal particles will desquamate from the support when the catalyst particles rub together, leading to a sharp decrease in the number of active sites. Therefore, designing an ideal nanostructure for supported noble metal catalysts which can overcome the two above-mentioned limitations and result in high stability is another key challenge in this field. Faced with these intractable problems, we and many other groups have recently focused on crystal planecontrolled synthesis of nanocatalysts as well as the design of ideal structures for stable nanocatalysts, in order to bring about new developments and a new generation of catalysts.

\subsection{Crystal plane-controlled synthesis of nano- catalysts}

Since controlling the crystal planes of nanomaterials is a paramount target in catalyst preparation, in recent years we have tried to synthesize nanocrystals with well-defined reactive crystal planes and exploit the relationship between specific crystal planes and catalytic properties [74-79]. Copper oxide $(\mathrm{CuO})$ is one of the most important catalysts and is widely used in environmental catalysis such as $\mathrm{CO}$ oxidation. Generally speaking, for monoclinic tenorite-structured $\mathrm{CuO}$ crystals, the close-packed $\{111\}$ planes have lower free energies and thus higher stability than the open $\{001\}$ and $\{01 \overline{1}\}$ planes. Consequently, the latter is anticipated to be more reactive than the former. Facile solutionbased methods were applied to synthesize $\mathrm{CuO}$ nanocrystals with different morphologies as shown in Figs. 10(a)-(c). Selected area electron diffraction (SAED) and HRTEM analysis were used to determine the structure of these samples. The results showed that $\mathrm{CuO}$ nanoparticles predominantly exposed the close-packed $\{111\}$ planes of the monoclinic structure (Fig. 10(d)), CuO nanobelts predominantly exposed the $\{001\}$ planes (Fig. 10(e)), while the $\mathrm{CuO}$ nanoplatelets predominantly exposed the $\{01 \overline{1}\}$ planes (Fig. 10(f)). In order to compare the reactivity of these $\mathrm{CuO}$ nanocrystals, we evaluated their catalytic performance for $\mathrm{CO}$ oxidation. Figure $10(\mathrm{~g})$ illustrates the specific rates of $\mathrm{CO}$ conversion over the various $\mathrm{CuO}$ nanocatalysts. At $110{ }^{\circ} \mathrm{C}$, the specific reaction rates were 1.0, 2.0, and $6.4 \times 10^{-8} \mathrm{~mol}_{\mathrm{Co}} /\left(\mathrm{m}_{\text {cat }}^{2} \mathrm{~s}\right)$ for the particles, belts, and platelets, respectively; that is, the rate for the nanoplatelets was over six times higher than that for the nanoparticles and roughly three times higher than that for the nanobelts. This 

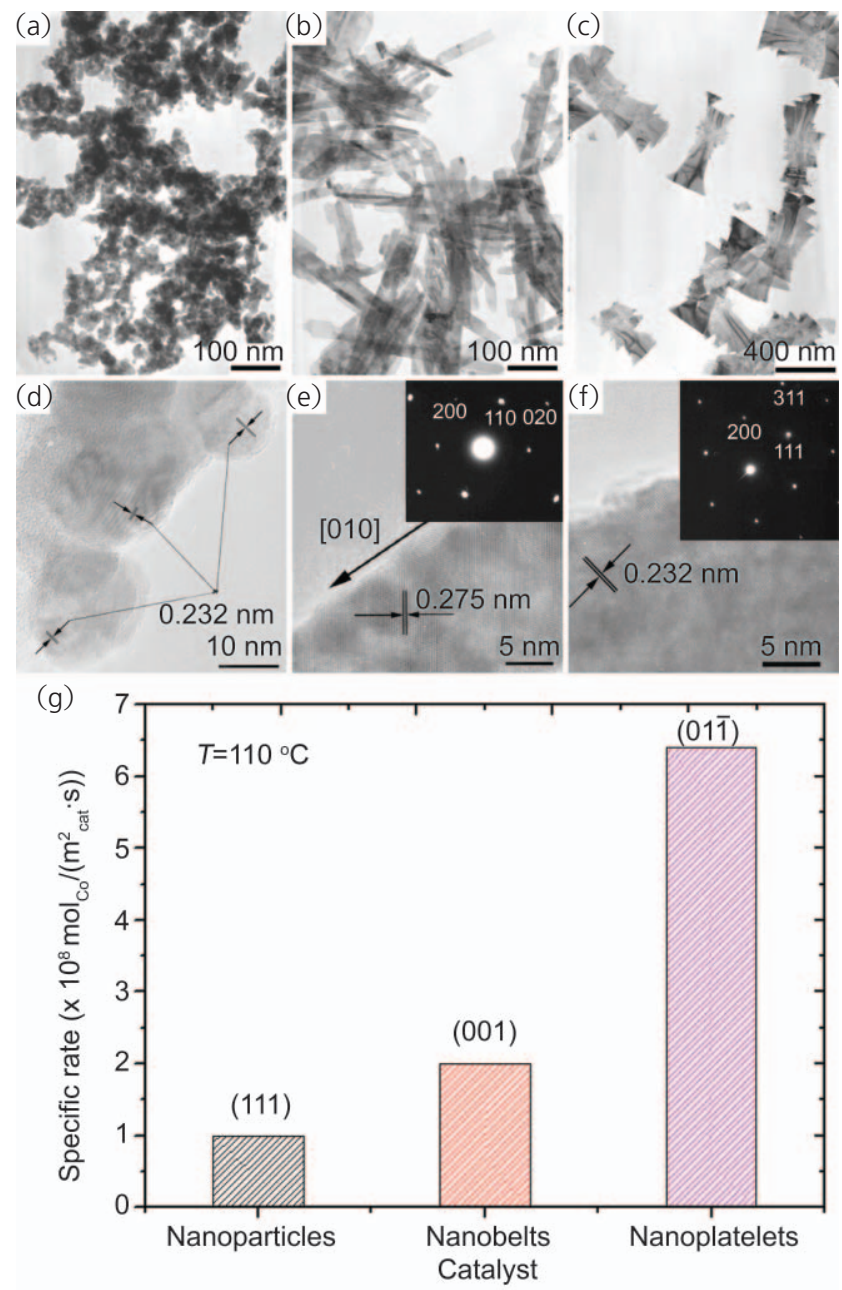

Figure 10 TEM images of (a) CuO nanoparticles; (b) CuO nanobelts; (c) CuO nanoplatelets; (d) HRTEM image of CuO nanoparticles; (e) HRTEM image of a typical CUO nanobelt viewed along [001], inset: the SAED pattern; (f) HRTEM image of a typical CuO nanoplatelet viewed along [01], inset: the SAED pattern; (g) specific rate of $\mathrm{CO}$ conversion over $\mathrm{CuO}$ nanoparticles, nanobelts and nanoplatelets at $110^{\circ} \mathrm{C}$. Adapted from Ref. [78]

suggests that the $\{01 \overline{1}\}$ planes of $\mathrm{CuO}$ nanocrystals showed the highest catalytic activity for $\mathrm{CO}$ oxidation and stimulated us to prepare $\mathrm{CuO}$ nanocatalysts with high ratio of $\{01 \overline{1}\}$ crystal planes [78].

Another of our studies involved Ag metal catalysts which have become increasingly important in the oxidation of olefins for the synthesis of industrially interesting products, such as epoxides and aldehydes [79]. In the study, truncated triangular, cubic, and "near spherical" Ag nanoparticles with well-defined crystal planes were synthesized by solution-based polyol processes. From TEM, SEM, and SAED analysis, as shown in Fig. 11, the as-
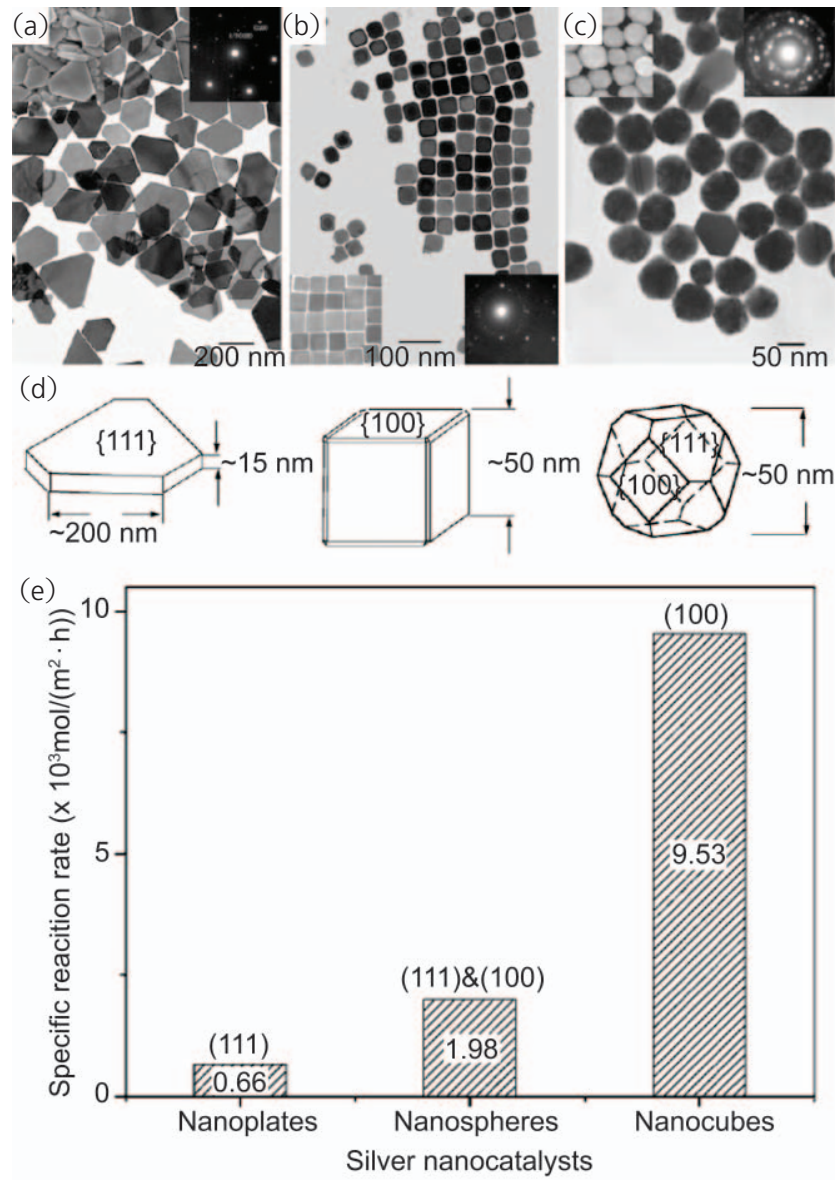

Figure 11 TEM images of (a) truncated triangular nanoplates; (b) nanocubes; (c) "near spherical" silver nanoparticles; (d) the corresponding structural models; (e) specific reaction rates of styrene conversion over truncated triangular nanoplates, "near spherical" nanoparticles, and cubic silver nanoparticles. Adapted from Ref. [79]

obtained truncated triangular Ag nanoplates with an average edge length of $200 \mathrm{~nm} \pm 20 \mathrm{~nm}$ and a thickness of about $15 \mathrm{~nm} \pm 5 \mathrm{~nm}$ predominantly exposed the most stable $\{111\}$ planes of the face centered cubic (fcc) structure (Fig. 11(a)); the slightly truncated Ag nanocubes had a mean edge length of $50 \mathrm{~nm} \pm 5 \mathrm{~nm}$ with smooth faces and each cube was a single crystal bounded mainly by six less stable $\{100\}$ planes (Fig. 11(b)); while the "near spherical" Ag nanoparticles with an average diameter of $70 \mathrm{~nm}$ $\pm 5 \mathrm{~nm}$ were composed of numerous $\{111\}$ and $\{100\}$ planes (Fig. 11(c)). The as-prepared Ag nanoparticles were used as catalysts for styrene oxidation and the specific reaction rates over the three types of nanoparticles were calculated and shown in Fig. 11(e), from which we can see that the rate for the 
nanocubes was over seven times higher than that for the nanoplates and three times higher than that for "near spherical" nanoparticles. The cube-shaped Ag nanocatalysts showed much higher styrene oxidation activity than the truncated triangular nanoplates and "near spherical" nanoparticles because they expose more reactive $\{100\}$ crystal planes.

The crystallographic planes of nanocatalysts not only greatly determine their catalytic activity, but also have significant influences on the reaction selectivity. Somorjai and co-workers investigated nanoparticle surface effects in benzene hydrogenation by comparing kinetic results for cubic and cuboctahedral Pt nanoparticles [80]. A tetradecyltrimethylammonium bromide (TTAB)-assisted solution phase method was adopted for the preparation of cubic $\mathrm{Pt}$ particles with a size of $12.3 \mathrm{~nm} \pm 1.4 \mathrm{~nm}$ consisting of only $\mathrm{Pt}(100)$ faces and cuboctahedral Pt particles with a size of $13.5 \mathrm{~nm} \pm 1.5 \mathrm{~nm}$ consisting of both $\mathrm{Pt}(100)$ and $\mathrm{Pt}(111)$ faces. Benzene hydrogenation studies demonstrated that both cyclohexene and cyclohexane formed on cuboctahedral nanoparticles whilst only cyclohexane was formed on cubic nanoparticles. This result showed that catalytic selectivity is also strongly affected by nanoparticle crystal planes. Therefore, in order to obtain nanocatalysts with optimized performance, we should prepare nanocrystals consisting of desired crystallographic planes which provide the highest catalytic activity as well as selectivity.

\subsection{Design of ideal structures for stable nano- catalysts}

Our efforts to overcome another obstacle facing the use of high quality nanocatalysts focus on improving their stability, especially for supported noble metal catalysts. Traditionally, supported catalysts were obtained by the deposition-precipitation method [81-83]. Although the as-prepared catalysts had high dispersions and metal loadings, they had poor stability due to aggregation of metal particles as well as desquamation of particles from the supports. To address these problems, metal particles should be effectively separated from each other and firmly fixed on the supports. Considering this point, porous structured materials might be a good choice for the supports. Actually, mesoporous materials with high internal surface areas, large and uniform pore sizes, and well-defined pore topologies have been widely used in catalysis in the past decades [8487]. However, the conventional synthetic strategies of embedding the pre-prepared metal particles in the mesoporous supports or in situ generation of nanoparticles via reduction of metal ions in the supports cannot yet provide nanocatalysts with excellent stability performance [88, 89]. For these reasons, we have tried to exploit a new strategy to fabricate nanocatalysts. In nanosystems, selfassembly offers one of the few practical strategies for assembling components into larger, functional ensembles through different interactions [90]. Based on this strategy, we have developed a novel bottom-up route to design ideal structures for stable nanocatalysts, namely, using "artificial atoms" (monodisperse nanocrystals, NCs) as uniform building blocks to construct mesoporous structures [53, 54, 91].

In the process, we first synthesized various nanocrystals via solution-based methods as described in Section 1. Then, a general emulsionbased bottom-up self-assembly (EBS) approach was carried out to assemble various kinds of nanocrystal building blocks with different composition, shape, size, and surfactant ligands into 3-D colloidal spheres [91]. Figure 12(a) illustrates this assembly strategy. The basic idea is to use microemulsion oil droplets as confined templates within which the nanocrystals are assembled by the evaporation of low boiling point solvents. We created a stable oil-in-water microemulsion system where the oil phase contained pre-synthesized well-dispersed nanocrystals encapsulated in ligands such as oleic acid or ODA and the aqueous solution contained hydrophilic surfactants such as cetyltrimethylammonium bromide (CTAB) or sodium dodecylsulfonate (SDS). By means of vigorous stirring or ultrasonic treatment the low boiling point solvent such as cyclohexane was evaporated from the microemulsion system. With the evaporation of the low boiling point solvent, the nanocrystals confined in 3-D oil microemulsion droplets were concentrated and assembled into 


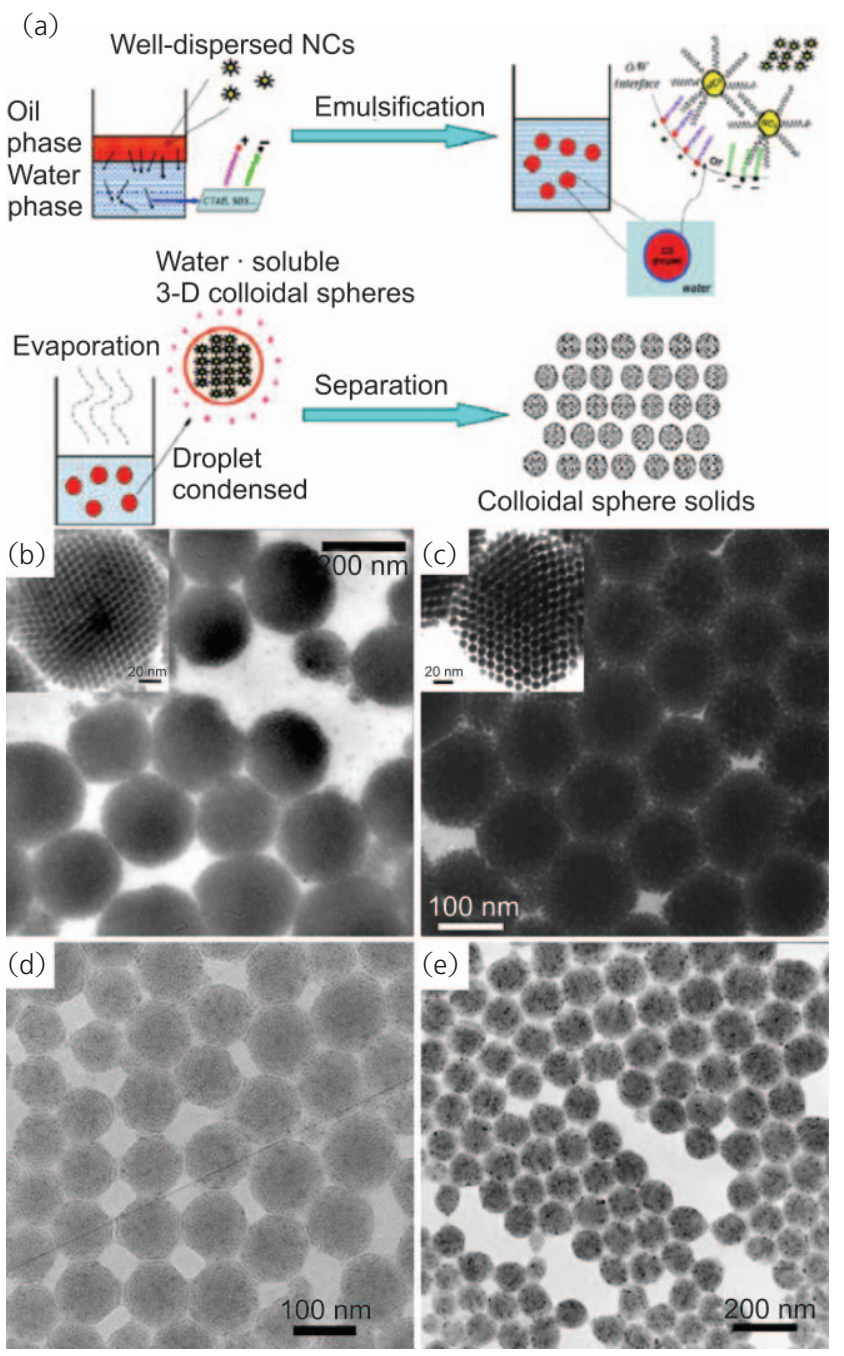

Figure 12 (a) Schematic illustration of the emulsion-based bottomup self-assembly (EBS) procedure. TEM images of as-obtained 3-D colloidal spheres of (b) $\mathrm{Ag}$; (c) $\mathrm{Ag}_{2} \mathrm{~S}$ (adapted from Ref. [53]; (d) $\mathrm{ZrO}_{2}$; (e) $\mathrm{NaYF}_{4}$ (adapted from Ref. [91])

3-D colloid spheres. By designing proper solution phase nanocrystals, surfactant and oil/water twophase systems, and controlling the emulsion and evaporation process, a series of 3-D colloidal spheres can be assembled from nanocrystal building blocks including metals, semiconducting metal chalcogenides, metal oxides, and rare earth compounds. Figures 12(b)-(e) show TEM images of representative colloidal spheres assembled from $\mathrm{Ag}, \mathrm{Ag}_{2} \mathrm{~S}, \mathrm{ZrO}_{2}$, and $\mathrm{NaYF}_{4}$, respectively. In order to obtain the eventual mesoporous structures, the surfactants were removed by calcining the asprepared colloidal spheres. The whole process can be concisely described by the scheme shown in Fig.

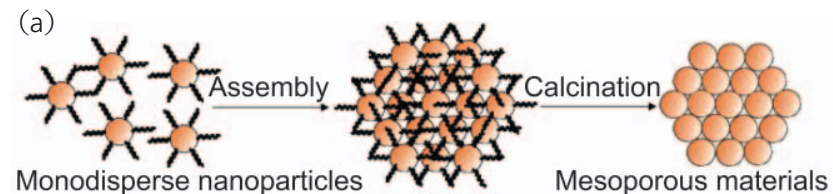

Monodisperse nanoparticles
Colloidal spheres

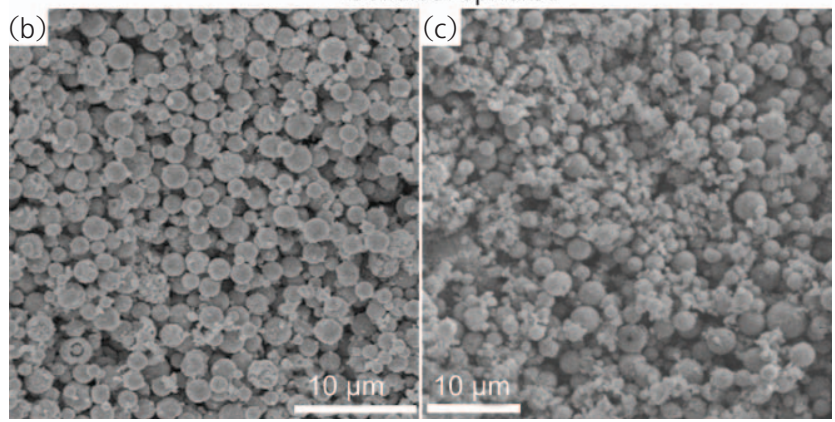

Figure 13 (a) Schematic illustration of the general strategy for preparation of mesoporous materials. Adapted from Ref. [53]. SEM images of as-obtained mesoporous products (b) NiO; (c) $\mathrm{MnO}$. Adapted from Ref. [54]

13(a) and, as examples, SEM images of mesoporous $\mathrm{NiO}$ and $\mathrm{MnO}$ spheres are shown in Figs. 13(b) and 3(c). Brunauer-Emmett-Teller (BET) and Barrett -Joyner-Halenda (BJH) analysis confirmed that mesopores were present in these materials and that their surface area was increased greatly compared to that of disassembled nanocrystals.

This bottom-up procedure provides us with a novel synthetic strategy for mesoporous structures, which has many advantages. First, since the assembly process occurs irrespective of the kind of nanocrystals, this route is very versatile. Second, the process is simple and easily controlled, and we can adjust the pore size by tuning the size of the nanocrystals to satisfy different catalytic reactions. More importantly, we can even synthesize hybrid mesoporous materials by mixing two or more kinds of crystals in the assembly process. For example, by assembling metal particles and metal oxide nanocrystals (the support) at the same time, we can obtain supported noble metal nanocatalysts with hybrid mesoporous structures as described in Fig. 14. In such a structure, the metal particles can be effectively separated from each other and firmly fixed in the mesostructure. This structure is hence expected to successfully prevent aggregation of metal particles and desquamation from the support, and thus increase the stablility of catalytic performance. 


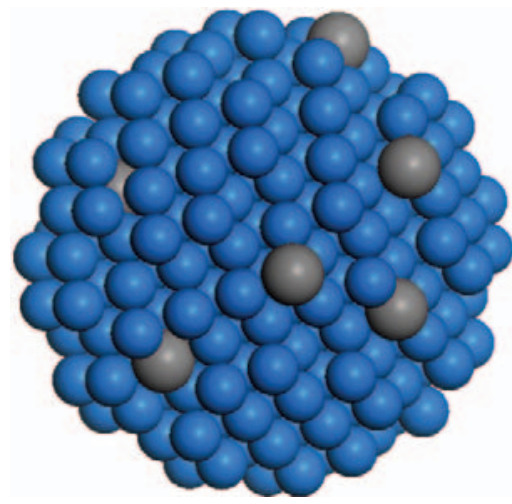

Figure 14 Schematic depiction of the idealized structure for supported noble metal nanocatalysts

\section{Conclusions and perspective}

This article provides an overview of some recent developments in our group related to solution-based synthesis of nanocrystals and their applications as nanocatalysts. Compared to physical methods and gas-phase strategies, the solution phase routes are much more easily controlled and can produce nanomaterials in a facile and large scale way. They are powerful ways of preparing various kinds of nanostructures to satisfy the needs of different applications in various fields, including $0-D$ nanocrystals which are ideal building blocks for constructing advanced and functional architectures, 1-D nanowires and nanorods which have efficient transport of electrons and excitons and thus potential applications in optical and electronic devices, hollow structures which are promising candidates for drug delivery and nanometer-scale reactors due to their great potential for the encapsulation of guest molecules, and superlattice structures which combine the properties of individual nanocrystals with new collective physical and chemical properties and provide the basis for the nanomaterials and nanodevices of the future.

For materials at the nanoscale, it is usually quite right that "structure dictates function". This tenet can be applied in nanocatalysis. The exposed crystal planes of nanocatalysts determine, to a great extent, their catalytic properties including activity and selectivity. Hence, it is very desirable to synthesize nanocatalysts with high ratios of more reactive crystal planes. Unfortunately, surfaces with high reactivity usually diminish rapidly during the crystal growth process as a result of the minimization of surface energy because the planes with higher surface energy are more reactive. Although the wet routes are evidenced to be more effective in generating nanomaterials than the dry ones, the crystal nucleation and growth process in the solution phase is very complex. In order to achieve rational control over the nanocrystals, it is urgently necessary to fully understand the nature of the crystal structure and the mechanism of chemical reactions as well as to precisely adjust the thermodynamic and kinetic parameters. For example, large high quality anatase $\mathrm{TiO}_{2}$ single crystals with a high percentage of more reactive $\{001\}$ planes have not been available until very recently, when $\mathrm{Lu}$ and co-workers prepared truncated anatase bipyramids using an aqueous solution containing titanium tetrafluoride $\left(\mathrm{TiF}_{4}\right)$ and hydrofluoric acid as the precursor and crystallographic controlling agent, respectively, in the synthesis of anatase single crystals by a hydrothermal route. The percentage of $\{001\}$ planes in these anatase bipyramids can be tuned from $35 \%$ to $47 \%$ through changing the concentration of TiF4 and the hydrothermal reaction time. Therefore, via proper solution-based strategies, the goal of rational control over the crystal growth process and preparation of nanocatalysts with desired crystal planes can be fulfilled, although there still remain great challenges to be overcome.

Nowadays, nanoscience and nanotechnology as well as applications of nanocrystals in catalysis are being developed at a great pace all over the world. However, we are at all times "preparing" nanocatalysts, that is, we first synthesize many catalysts and then choose the best one by testing and comparing their catalytic properties. This is an inefficient way. What scientists must pursue is the "design" rather than the "preparation" of nanocatalysts. The ideal way is to first fully understand the relationship between crystal structure and corresponding catalytic properties, and then synthesize nanocatalysts with well-defined reactive crystal planes and desired nanostructures based on advanced nanosynthetic techniques. Although the present-day techniques are far from satisfactory, we 
believe that further investigation can bring a bright future for this field.

\section{Acknowledgements}

This work was supported by NSFC (90606006), the State Key Project of Fundamental Research for Nanoscience and Nanotechnology (2006CB932300), and the Key Grant Project of the Ministry of Education of P. R. China (No. 306020).

\section{Reference}

[1] Alivisatos, A. P. Semiconductor clusters, nanocrystals, and quantum dots. Science 1996, 271, 933-937.

[2] Murray, C. B.; Kagan, C. R.; Bawendi, M. G. Synthesis and characterization of monodisperse nanocrystals and close-packed nanocrystal assemblies. Annu. Rev. Mater. Sci. 2000, 30, 545-610.

[3] Xia, Y.; Yang, P.; Sun, Y.; Wu, Y.; Mayers, B.; Gates, B.; Yin, Y.; Kim, F.; Yan, H. One-dimensional nanostructures: Synthesis, characterization, and applications. Adv. Mater. 2003, 15, 353-389.

[4] El-Sayed, M. A. Small is different: Shape-, size-, and composition-dependent properties of some colloidal semiconductor nanocrystals. Acc. Chem. Res. 2004, 37, 326-333.

[5] Huang, Y.; Duan, X. F.; Lieber, C. M. Nanowires for integrated multicolor nanophotonics. Smal/ 2005, 1, 142 -147 .

[6] Lai, E.; Kim, W.; Yang, P. D. Vertical nanowire array-based light emitting diodes. Nano Res. 2008, 1, 123-128.

[7] Roduner, E. Size matters: Why nanomaterials are different. Chem. Soc. Rev. 2006, 35, 583-592.

[8] Hu, J. T.; Odom, T. W.; Lieber, C. M. Chemistry and physics in one dimension: Synthesis and properties of nanowires and nanotubes. Acc. Chem. Res. 1999, 32, 435-445.

[9] Cui, Y.; Wei, Q. Q.; Park, H. K.; Lieber, C. M. Nanowire nanosensors for highly sensitive and selective detection of biological and chemical species. Science 2001, 293, 1289-1292.

[10] Liu, Z. Robinson, J. T.; Sun, X. M.; Dai, H. J. PEGylated nanographene oxide for delivery of water-insoluble cancer drugs. J. Am. Chem. Soc. 2008, 130, 1087610877.

[11] Wang, Z. L. Energy harvesting for self-powered nanosystems. Nano Res. 2008, 1, 1-8.

[12] Huang, W.; Kuhn, J. N.; Tsung, C. K.; Zhang, Y.; Habas, S. E.; Yang, P.; Somorjai, G. A. Dendrimer templated synthesis of one nanometer Rh and Pt particles supported on mesoporous silica: Catalytic activity for ethylene and pyrrole hydrogenation. Nano Lett. 2008, 8, 2027-2034.

[13] Sun, X. M.; Liu, Z.; Welsher, K.; Robinson, J. T.; Goodwin, A.; Zaric, S.; Dai, H. J. Nano-graphene oxide for cellular imaging and drug delivery. Nano Res. 2008, 1, 203-212.

[14] Gao, X.; Cui, Y.; Levenson, R. M.; Chung, L. W. K.; Nie, S. In vivo cancer targeting and imaging with semiconductor quantum dots. Nat. Biotechnol. 2004, 22, 969-976.

[15] Tian, B.; Zheng, X.; Kempa, T. J.; Fang, Y.; Yu, N.; Yu, G.; Huang, J.; Lieber, C. M. Coaxial silicon nanowires as solar cells and nanoelectronic power sources. Nature 2007, 449, 885-889.

[16] Tian, N.; Zhou, Z. Y.; Sun, S. G.; Ding, Y.; Wang, Z. L. Synthesis of tetrahexahedral platinum nanocrystals with high-index facets and high electro-oxidation activity. Science, 2007, 316, 732-735.

[17] Liu, F. K.; Huang, P. W.; Chang, Y. C.; Ko, F. H.; Chu, T. C. Combining optical lithography with rapid microwave heating for the selective growth of Au/Ag bimetallic core/shell structures on patterned silicon wafers. Langmuir 2005, 21, 2519-2525.

[18] Bhuvana, T.; Kulkarni, G. U. Highly conducting patterned $\mathrm{Pd}$ nanowires by direct-write electron beam lithography. ACS Nano 2008, 2, 457-462.

[19] Ge, J. P.; Li, Y. D. Selective atmospheric pressure chemical vapor deposition route to CdS arrays, nanowires, and nanocombs. Adv. Funct. Mater. 2004, 14, 157-162.

[20] Ge, J. P.; Wang, J.; Zhang, H. X.; Li, Y. D. A general atmospheric pressure chemical vapor deposition synthesis and crystallographic study of transition metal sulfide one-dimensional nanostructures. Chem. Eur. J. 2004, 10, 3525-3530.

[21] Li, X. L.; Ge, J. P.; Li, Y. D. Atmospheric pressure chemical vapor deposition: An alternative route to large-scale $\mathrm{MoS}_{2}$ and $\mathrm{WS}_{2}$ inorganic fullerene-like nanostructures and nanoflowers. Chem. Eur. J. 2004, 10, 6163-6171.

[22] Ge, J. P.; Wang, J.; Zhang, H. X.; Wang, X.; Peng, Q.; Li, Y. D. Halide-transport chemical vapor deposition of luminescent $\mathrm{ZnS}: \mathrm{Mn}^{2+}$ one-dimensional nanostructures. Adv. Funct. Mater. 2005, 15, 303-308. 
[23] Jin, R. C.; Cao, Y. W.; Mirkin, C. A.; Kelly, K. L.; Schatz, G. C.; Zheng, J. G. Photoinduced conversion of silver nanospheres to nanoprisms. Science 2001, 294, 19011903.

[24] Yin, Y. D.; Alivisatos, A. P. Colloidal nanocrystal synthesis and the organic-inorganic interface. Nature 2005, 437, 664-670.

[25] Murphy, C. J.; Sau, T. K.; Gole, A. M.; Orendorff, C. J. G.; Gou, J. L.; Hunyadi, S. E.; Li, T. Anisotropic metal nanoparticles: Synthesis, assembly, and optical applications. J. Phys. Chem. B 2005, 109, 13857-13870.

[26] Murray, C. B.; Norris, D. J.; Bawendi, M. G. Synthesis and characterization of nearly monodisperse $\mathrm{CdE}(\mathrm{E}=\mathrm{S}$, Se, Te) semiconductor nanocrystallites. J. Am. Chem. Soc. 1993, 115, 8706-8715.

[27] Donegá, C. M.; Liljeroth, P.; Vanmaekelbergh, D. Physicochemical evaluation of the hot-injection method, a synthesis route for monodisperse nanocrystals. Small 2005, 1, 1152-1162.

[28] Jun, Y.; Choi, J.; Cheon, J. Shape control of semiconductor and metal oxide nanocrystals through nonhydrolytic colloidal routes. Angew. Chem. Int. Ed. 2006, 45, 3414-3439.

[29] Rao, C. N. R.; Vivekchand, S. R. C.; Biswas, K.; Govindaraj, A. Synthesis of inorganic nanomaterials. Dalton Trans. 2007, 3728-3749.

[30] Pinna, N.; Niederberger, M. Surfactant-free nonaqueous synthesis of metal oxide nanostructures. Angew. Chem. Int. Ed. 2008, 47, 5292-5304.

[31] Yoshimura, M.; Byrappa, K. Hydrothermal processing of materials: Past, present and future. J. Mater. Sci. 2008, 43, 2085-2103.

[32] Sun, S.; Zeng, H.; Robinson, D. B.; Raoux, S.; Rice, P. M.; Wang, S. X.; Li, G. Monodisperse $\mathrm{MFe}_{2} \mathrm{O}_{4}(\mathrm{M}=\mathrm{Fe}, \mathrm{Co}$, Mn) nanoparticles. J. Am. Chem. Soc. 2004, 126, 273279.

[33] Wang, D. S.; Liang, X.; Li, Y. D. Preparation of nearly monodisperse nanoscale inorganic pigments. Chem. Asian J. 2006, 1, 91-94.

[34] Park, J.; Joo, J.; Kwon, S. G.; Jang, Y.; Hyeon, T. Synthesis of monodisperse spherical nanocrystals. Angew. Chem. Int. Ed. 2007, 46, 4630-4660.

[35] Lee, E. P.; Xia, Y. N. Growth and patterning of Pt nanowires on silicon substrates. Nano Res. 2008, 1, 129-137.

[36] Hsu, Y. F.; Xi, Y. Y.; Tam, K. H.; Djurisic, A. B.; Luo, J. M.; Ling, C. C.; Cheung, C. K.; Ng, A. M. C.; Chan, W. K.;
Deng, X.; Beling, C. D.; Fung, S.; Cheah, K. W.; Fong, P. W. K.; Surya, C. C. Undoped p-type ZnO nanorods synthesized by a hydrothermal method. Adv. Funct. Mater. 2008, 18, 1020-1030.

[37] Hu, M. J.; Lin, B.; Yu, S. H. Magnetic field-induced solvothermal synthesis of one-dimensional assemblies of $\mathrm{Ni}$-Co alloy microstructures. Nano Res. 2008, 1, 303313.

[38] Burda, C.; Chen, X.; Narayanan, R.; El-Sayed, M. A. Chemistry and properties of nanocrystals of different shapes. Chem. Rev. 2005, 105, 1025-1102.

[39] Bruchez, M.; Moronne, M.; Gin, P.; Weiss, S.; Alivisatos, A. P. Semiconductor nanocrystals as fluorescent biological labels. Science 1998, 281, 2013-2016.

[40] Kuo, C. H.; Chen, C. H.; Huang, M. H. Seed-mediated synthesis of monodispersed $\mathrm{Cu}_{2} \mathrm{O}$ nanocubes with five different size ranges from 40 to $420 \mathrm{~nm}$. Adv. Funct. Mater. 2007, 17, 3773-3780.

[41] Tao, A. R.; Habas, S.; Yang, P. Shape control of colloidal metal nanocrystals. Small 2008, 4, 310-325.

[42] Viswanatha, R.; Battaglia, D. M.; Curtis, M. E.; Mishima, T. D.; Johnson, M. B.; Peng, X. G. Shape control of doped semiconductor nanocrystals (d-dots). Nano Res. 2008, 1 , 138-144.

[43] Xie, T.; Li, S.; Wang, W. B.; Peng, Q.; Li, Y. D. Nucleation and growth of $\mathrm{BaF}_{x} \mathrm{Cl}_{2-x}$ nanorods. Chem. Eur. J. 2008, 14, 9730-9735.

[44] Zhang, H. W.; Delikanli, S.; Qin, Y. L.; He, S. L.; Swihart, M.; Zeng, H. Synthesis of monodisperse CdS nanorods catalyzed by Au nanoparticles. Nano Res. 2008, 1, 314320.

[45] Xie, T.; Li, S.; Peng, Q.; Li, Y. D. Monodisperse BaF nanocrystals: phase, size transition and self-assembly. Angew. Chem. Int. Ed. 2009, 48, 196-200.

[46] Peng, X. G.; Manna, L.; Yang, W. D.; Wickham, J.; Scher, E.; Kadavanich, A.; Alivisatos, A. P. Shape control of CdSe nanocrystals. Nature 2000, 404, 59-61.

[47] Yin, M.; O'Brien, S. Synthesis of monodisperse nanocrystals of manganese oxides. J. Am. Chem. Soc. 2003, 125, 10180-10181.

[48] Park, J.; Lee, E.; Hwang, N. M.; Kang, M.; Kim, S. C.; Hwang, Y.; Park, J. G.; Noh, H. J.; Kim, J. Y.; Park, J. H.; Hyeon, T. One-nanometer-scale size-controlled synthesis of monodisperse magnetic iron oxide nanoparticles. Angew. Chem. Int. Ed. 2005, 44, 2872-2877.

[49] Park, J.; An, K.; Hwang, Y.; Park, J. G.; Noh, H. J.; Kim, J. 
Y.; Park, J. H.; Hwang, N. M.; Hyeon, T. Ultra-large-scale syntheses of monodisperse nanocrystals. Nat. Mater. 2004, 3, 891-895.

[50] Wang, X.; Zhuang, J.; Peng, Q.; Li, Y. D. A general strategy for nanocrystal synthesis. Nature 2005, 437, 121-124.

[51] LaMer, V. K.; Dinegar, R. H. Theory, production and mechanism of formation of monodispersed hydrosols. J. Am. Chem. Soc. 1950, 72, 4847-4854.

[52] Huo, Z. Y.; Chen, C.; Liu, X. W.; Chu, D. R.; Li, H. H.; Peng, Q.; Li, Y. D. One-pot synthesis of monodisperse $\mathrm{CeO}_{2}$ nanocrystals and superlattices. Chem. Commun. 2008, 3741-3743.

[53] Wang, D. S.; Xie, T.; Peng, Q.; Li, Y. D. Ag, $\mathrm{Ag}_{2} \mathrm{~S}$, and $\mathrm{Ag}_{2}$ Se nanocrystals: Synthesis, assembly, and construction of mesoporous structures. J. Am. Chem. Soc. 2008, 130, 4016-4022.

[54] Wang, D. S.; Xie, T.; Peng, Q.; Li, Y. D. Direct thermal decomposition of metal nitrates in octadecylamine to metal oxide nanocrystals. Chem. Eur. J. 2008, 14, 25072513.

[55] Wang, D. S.; Zheng, W.; Hao, C. H.; Peng, Q.; Li, Y. D. General synthesis of $\mathrm{I}-\mathrm{III}-\mathrm{VI}_{2}$ ternary semiconductor nanocrystals. Chem. Commun. 2008, 2556-2558.

[56] Wang, D. S.; Hao, C. H.; Zheng, W.; Peng, Q.; Wang, T. H.; Liao, Z. M.; Yu, D. P.; Li, Y. D. Ultralong singlecrystalline $\mathrm{Ag}_{2} \mathrm{~S}$ nanowires: Promising candidates for photoswitches and room-temperature oxygen sensors. Adv. Mater. 2008, 20, 2628-2632.

[57] Tan, Y. W.; Xue, X. Y.; Peng, Q.; Zhao, H.; Wang, T. H.; Li, $Y$. D. Controllable fabrication and electrical performance of single crystalline $\mathrm{Cu}_{2} \mathrm{O}$ nanowires with high aspect ratios. Nano Lett. 2007, 7, 3723-3728.

[58] Chen, W.; Peng, Q.; Li, Y. D. Alq 3 nanorods: Promising building blocks for optical devices. Adv. Mater. 2008, 20, 2747-2750.

[59] Chen, W.; Peng, Q.; Li, Y. D. Luminescent bis-(8hydroxyquinoline) cadmium complex nanorods. Cryst. Growth Des. 2008, 8, 564-567.

[60] Liang, X.; Wang, X.; Zhuang, Y.; Xu, B.; Kuang, S. M.; Li, $Y$. D. Formation of $\mathrm{CeO}_{2}-\mathrm{ZrO}_{2}$ solid solution nanocages with controllable structures via Kirkendall effect. J. Am. Chem. Soc. 2008, 130, 2736-2737.

[61] Liang, X.; Xu, B.; Kuang, S. M.; Wang, X. Multifunctionalized inorganic-organic rare earth hybrid microcapsules. Adv. Mater. 2008, 20, 3739-3744.
[62] Zhuang, Z. B.; Peng, Q.; Wang, X.; Li, Y. D. Tetrahedral colloidal crystals of $\mathrm{Ag}_{2} \mathrm{~S}$ nanocrystals. Angew. Chem. Int. Ed. 2007, 46, 8174-8177.

[63] Zhuang, Z. B.; Peng, Q.; Zhang, B.; Li, Y. D. Controllable synthesis of $\mathrm{Cu}_{2} \mathrm{~S}$ nanocrystals and their assembly into a superlattice. J. Am. Chem. Soc. 2008, 130, 1048210483.

[64] Haruta, M.; Yamada, N.; Kobayashi, T.; Lijima, S. Gold catalysts prepared by co-precipitation for lowtemperature oxidation of hydrogen and of carbon monoxide. J. Catal. 1989, 115, 301-309.

[65] Valden, M.; Lai, X.; Goodman, D. W. Onset of catalytic activity of gold clusters on titania with the appearance of nonmetallic properties. Science 1998, 281, 1647-1650.

[66] Thomas, J. M.; Johnson, B. F. G.; Raja, R.; Sankar, G.; Midgley, P. A. High-performance nanocatalysts for singlestep hydrogenations. Acc. Chem. Res. 2003, 36, 20-30.

[67] Chang, J. S.; Hwang, J. S.; Park, S. E. Preparation and application of nanocatalysts via surface functionalization of mesoporous materials. Res. Chem. Intermediat. 2003, 29, 921-938.

[68] Narayanan, R.; El-Sayed, M. A. Catalysis with transition metal nanoparticles in colloidal solution: Nanoparticle shape dependence and stability. J. Phys. Chem. B 2005, 109, 12663-12676.

[69] Chang, J. S.; Jhung, S. H.; Hwang, Y. K.; Park, S. E.; Hwang, J. S. Syntheses and applications of nanocatalysts based on nanoporous materials. Int. J. Nanotechnol. 2006, 3, 150-180.

[70] Choudary, B. M.; Mulukutla, R. S.; Klabunde, K. J. Benzylation of aromatic compounds with different crystallites of MgO. J. Am. Chem. Soc. 2003, 125, 20202021.

[71] Zhou, K. B.; Wang, X.; Sun, X. M.; Peng, Q.; Li, Y. D. Enhanced catalytic activity of ceria nanorods from welldefined reactive crystal planes. J. Catal. 2005, 229, 206212.

[72] Liu, J. F.; Chen, W.; Liu, X. W.; Zhou, K. B.; Li, Y. D. Au/ $\mathrm{LaVO}_{4}$ nanocomposite: Preparation, characterization, and catalytic activity for CO oxidation. Nano Res. 2008, 1, 46 -55 .

[73] Peng, S.; Lee, Y.; Wang, C.; Yin, H.; Dai, S.; Sun, S. H. A facile synthesis of monodisperse Au nanoparticles and their catalysis of CO oxidation. Nano Res. 2008, 1, 229234.

[74] Zhou, K. B.; Xu, R.; Sun, X. M.; Chen, H. D.; Tian, 
Q.; Shen, D. X.; Li, Y. D. Favorable synergetic effects between $\mathrm{CuO}$ and the reactive planes of ceria nanorods. Catal. Lett. 2005, 101, 169-173.

[75] Wang, D. S.; Xu, R.; Wang, X.; Li, Y. D. NiO nanorings and their unexpected catalytic property for $\mathrm{CO}$ oxidation. Nanotechnology 2006, 17, 979-983.

[76] Xu, R.; Wang, X.; Wang, D. S.; Zhou, K. B.; Li, Y. D. Surface structure effects in nanocrystal $\mathrm{MnO}_{2}$ and $\mathrm{Ag} /$ $\mathrm{MnO}_{2}$ catalytic oxidation of CO. J. Catal. 2006, 237, 426 -430 .

[77] Wang, D. S.; Wang, X.; Xu, R.; Li, Y. D. Shape-dependent catalytic activity of $\mathrm{CuO} / \mathrm{MgO}$ nanocatalysts. J. Nanosci. Nanotechnol. 2007, 7, 3602-3606.

[78] Zhou, K. B.; Wang, R. P.; Xu, B. Q.; Li, Y. D. Synthesis, characterization and catalytic properties of $\mathrm{CuO}$ nanocrystals with various shapes. Nanotechnology 2006, 17, 3939-3943.

[79] Xu, R.; Wang, D. S.; Zhang, J. T.; Li, Y. D. Shapedependent catalytic activity of silver nanoparticles for the oxidation of styrene. Chem. Asian J. 2006, 1, 888-893.

[80] Bratlie, K. M.; Lee, H.; Komvopoulos, K.; Yang, P.; Somorjai, G. A. Platinum nanoparticle shape effects on benzene hydrogenation selectivity. Nano Lett. 2007, 7, 3097-3101.

[81] Bond, G. C.; Thompson, D. T. Catalysis by gold. Catal. Rev. 1999, 41, 319-388.

[82] Toebes, M. L.; van Dillen, J. A.; De Jong, Y. P. Synthesis of supported palladium catalysts. J. Mol. Catal. A-Chem. 2001, 173, 75-98.

[83] Delannoy, L.; Weiher, N.; Tsapatsaris, N.; Beesley, A. M.; Nchari, L.; Schroeder, S. L. M.; Louis, C. Reducibility of supported gold (III) precursors: Influence of the metal oxide support and consequences for CO oxidation activity. Top. Catal. 2007, 44, 263-273.

[84] Kresge, C. T.; Leonowicz, M. E.; Roth, W. J.; Vartuli, J. C.; Beck, J. S. Ordered mesoporous molecular-sieves synthesized by a liquid-crystal template mechanism. Nature 1992, 359, 710-712.

[85] Tanev, P. T.; Chibwe, M. Titanium-containing mesoporous molecular sieves for catalytic oxidation of aromatic compounds. Nature 1994, 368, 321-323.

[86] Hu, Y. S.; Guo, Y. G.; Sigle, W.; Hore, S.; Balaya, P.; Maier, J. Electrochemical lithiation synthesis of nanoporous materials with superior catalytic and capacitive activity. Nat. Mater. 2006, 5, 713-717.

[87] Cejka, J.; Mintova, S. Perspectives of micro/mesoporous composites in catalysis. Catal. Rev. 2007, 49, 457-509.

[88] Zhang, S. B.; Wang, J. K.; Liu, H. T.; Wang, X. L. Onepot synthesis of $\mathrm{Ni}$-nanoparticle-embedded mesoporous titania/silica catalyst and its application for $\mathrm{CO}_{2}$-reforming of methane. Catal. Commun. 2008, 9, 995-1000.

[89] Xiong, H. F.; Zhang, Y. H.; Wang, S. G.; Liew, K. Y.; Li, J. L. Preparation and catalytic activity for Fischer-Tropsch synthesis of Ru nanoparticles confined in the channels of mesoporous SBA-15. J. Phys. Chem. C 2008, 112, 97069709.

[90] Phillips, J. M. Up close: Nanoscale science research centers. MRS Bull. 2006, 31, 44-49.

[91] Bai, F.; Wang, D. S.; Huo, Z. Y.; Chen, W.; Liu, L. P.; Liang, X.; Chen, C.; Wang, X.; Peng, Q.; Li, Y. D. A versatile bottom-up assembly approach to colloidal spheres from nanocrystals. Angew. Chem. Int. Ed. 2007, 46, 66506653. 